\title{
Establishing a Digital Topographic Database Using a High Resolution Imagery
}

\author{
Chris Adebola Odeyemi ${ }^{1, *}$, Adeyinka Jimoh Lamidi ${ }^{2}$, Taiwo Jimoh Oluboyede ${ }^{3}$ \\ The Federal Polytechnic, Department of Surveying \& Geo-informatics, Ado-Ekiti, Nigeria
}

Email address:

chrisodeyemi@gmail.com (Odeyemi, C. A.), lamidiadeyinka79@gmail.com (Adeyinka, L. J.), taiwo_oluboyede@yahoo.com (Oluboyede, T. J.)

\section{To cite this article:}

Chris Adebola Odeyemi, Adeyinka Jimoh Lamidi, Taiwo Jimoh Oluboyede. Establishing a Digital Topographic Database Using a High Resolution Imagery. International Journal of Science, Technology and Society. Vol. 3, No. 6, 2015, pp. $279-287$.

doi: $10.11648 /$ j.ijsts.20150306.12

\begin{abstract}
This paper takes an overview of the use of high reslution imageries for the establishment of digital topographic information, it also review some modern techniques of map making, using high resolution imageries. It shows that with the rapid and successful advances in remote sensing, GIS, and GPS technologies in the mapping sciences, coupled with the expected increase in the number of sensors for sub-meter (spatial) resolution satellite images, the sustainable development of Nigeria can be attained with the use of maps to achieve UN Sustainable Development Goals (SDG).
\end{abstract}

Keywords: ATKIS, Geographic Information System (GIS), Imagery, Maps, Remote Sensing

\section{Introduction}

Maps, especially topographical maps had always been an indispensable tools in National development, they had being used for centuries for many applications, which include urban planning, disaster management, natural resources management, environmental monitoring, graphic presentation and visualization of thematic data, base map for thematic maps (e.g. Geological Map). Traditional cartography, (the Art, Science and Technology of producing maps) had gone through dramatic changes in the last decade. The dissemination of information through map had moved from paper to digital format, this is because of technological development, especially in the field of Remote Sensing (RS), Geographic Information System (GIS) and information and Communication Technology (ICT), had brought about changes to ways in which geographic data is acquired, managed, processed, presented and disseminated to the users. Development in computer software's and multimedia technology had complemented the traditional way maps are produced and distributed.

GIS is a computer aided decision support and planning tool which integrate data from maps and other auxiliary information for a geographical area of interest. This is a rapidly advancing computer based technology where information is organized, analyzed and presented with reference to location. Once the GIS package integrate spatial and non-spatial attributes, the planner has a powerful tools, which can be used to analyze information circulation or transformation, as users can access the attributes of data at their fingertips. However, till date, most of the organizations are manually creating and utilizing a variety of maps in their daily activities.

Remote Sensing Technology is developing fast. Many new sensors have emerged in recent years, and the spatial dissolution is getting higher and higher. Landsat and SPOT images have been used in mapping at the scales of $1: 100,000,1: 50,000$ and 1:25,000. The map production includes digital terrain model (DTM), digital orthoimage, topographic maps. Presently, there is availability of high spatial resolution imageries from $1 \mathrm{~m}$ for IKONOS to $0.6 \mathrm{~m}$ for QuickBird images. This makes it possible to use these images for large scale mapping. The advantages of using space images include rapid acquisition of data covering large areas, frequent revisit times of the same location, the ability of collecting data in remote or restricted areas and relatively quick post-processing, also these can be used to reduced cost and increase efficiency (Huixian, 2005).

Digital topographic database is a special case of GIS and has recently evolved as a tool to collect, maintain store and 
reorganized as well as modeling and analyzing data dissemination of topographic information (Tempfli, 2003). Before the introduction of digital database technologies in national mapping agencies, the basic techniques used to generate and store spatial information were analogue, but nowadays, many mapping organizations are using digital technologies to produce digital maps. However, according to Ketele (2004) they have difficulties to transform themselves in more competitive and customer oriented services. They are still using the old notion of map sheets in their digital production environment as the spatial information system they introduce is mostly used to develop cartographic databases and thereby produce standard cartographic products. Topographic database, which stores the national and artificial landscape in the form of digital models, consists of landscape features at different level of detail. These may not be the exact representation of the landscape but they are not significantly generalized. The main aim of this research is to develop a digital topographic database, as compared to the production of digital topographic maps in sheets.

\subsection{Problems of Geo-Informatics (GI) Products in Nigeria}

The problem in Nigeria is that the Geo-information (GI) is not available in most cases or available in a state that limits its use. This dilemma is further accentuated by the fact that GI providers and users do not know which data or information is available in the country. The general situation of the GI industry in Nigeria is chaotic: maps are obsolete (over 40 years old!), most of the information that are available are in analogue form, at the same time money and efforts are being wasted by the private sector (especially oil companies) and the government in duplicative generation of new digital data sets, especially in the oil rich Niger Delta.

Citizens, private organizations and government agencies in Nigeria are demanding greater and faster access to reliable and up-to-date land information for their daily activities and business ventures. The major challenge is the creation of current map to meet the diversified needs of the users. When the information is available, the next step which cannot be separated from availability is accessibility to the information. There are many organizations involved in the processes of collection, storage and maintenance of cadastral and land registration information in Nigeria, these government agencies collect the relevant data and store them in a way that makes their retrieval cumbersome and in many cases impossible. The Maps and associated legal documents are usually damaged within a short period of time because of poor storage. In consequence, information though collected may be described as not available in many parts of Nigeria. (Akingbade, 2005)

The most often large scale topographic map in Nigeria is 1:50.000, most of the urban areas in Nigeria have been covered by 1:1250 scale topographic maps. However, due to the fast development in these areas, these topographic maps are out of date very fast. Hence, updating of these maps has become an important requirement. Furthermore, the geo-information products in new formats such as Digital Terrain Model (DTM) \& Digital Orthophoto Map (DOM) to provide more functions are necessary too.

The Federal Survey is the organization that produces topographic maps (all in analogue format for more than 40 years) and other geo-information products, and provides geo-information services all over the country, up till now, they apply the photogrammetric method using aerial photographs as the main data source for the production of Topographic Maps. Certainly, the aerial photogrammetric technique has made a great contribution to the surveying and mapping field. It is only by this means that mapping of a high percentage of the world is possible. Very accurate different kinds of maps can be made by these methods. During this process, costs have been reduced, and the efficiency has improved but some weaknesses of this technique are still there. Under the current conditions in Nigeria, the first of the weakness is that it is a timeconsuming. Proceeding from flight planning to obtaining the final analogue images in general, this procedure needs, at least, several months.

Furthermore, different flight missions for different mapping tasks due to the different scales in the same area are needed. The next weakness of this method is the capacity to orthorectify aerial photos and mosaic them into large scenes (usually 1:25,000 scale aerial photographs are used for 1:50,000 mapping in Nigeria, so around 4 stereo pairs needed to be mosaic to form one Orthophoto). Some other weaknesses are also there, such as limited capacity of flying (availability of aircraft, cameras, etc) difficult to fly in some special areas, weather conditions, problem of relief displacement especially at the corners of the photo, lower radiometric and spectral resolution.

As the urban areas are developing rapidly, and user's demands are also increasing very fast, a higher capability of providing topographic maps and other geo-information products with a better manner are required. It Is therefore, very important to find an alternative method to meet this requirement. This research tires to investigate such an alternative method.

Presently, a great progress is being made in satellite imaging techniques. The continuous improvements in spatial, temporal, spectral and radiometric resolution and the enhancement of the ability in image processing are the major aspects. Especially, high photographs for producing and updating the geo-information products, in direct competition to aerial images. The table below lists some of the high resolution RS (Remote Sensing) sensors currently.

The launch of these sensors opens a new era of high resolution satellite imagery collection and can also promote the mapping applications from satellite images. In theory, the use of high resolution imagery for making maps and other types of geo-information products could overcome many weaknesses of aerial photogrammetric method. Firstly, satellite images are very up-to-date due to short revisit period to earth and we can obtain the images very 
quickly from the agencies involved in the field of satellite images acquisition via internet through file transfer protocol (FTP) or other means like CD-ROMS. Secondly, due to a very large footprint comparing to aerial photographs, high resolution satellite images covering large area can be collected in one time, it is effective in map compilation. Especially for the production of orthophotos,there are many other features of satellite images for example no need flying planning, no limitation of special areas, having important value especially for the remote area or area in bad condition for control survey or very developed area or urgent updating more or less easier for orthorectification.

Table 1. Very high-resolution civilian space sensors.

\begin{tabular}{lllllll}
\hline Sensor & Company & Launch & Mode & Pixel size at nadir & Height (Km) & Swath (km) \\
\hline IKONOS 2 & Space imaging & 1999 & PAN/4MS & 0.82 .3 .28 & 680 & 11 \\
EROS A & Images sat Int. & 2000 & PAN & 1.8 & 600 & 12.6 \\
Quick Bird & Digital globe & 2001 & PAN/4MS & 0.61 .244 & 450 & 16.5 \\
Tes & ISRO, India & 2001 & PAN & 1.0 & 565 & 12 \\
SPORTS 5 & SPORT image & 2002 & PAN/4MS & $5(2.5) 10$ & 830 & 12 \\
Orb view 3 & Orbimage & 2003 & PAN/4MS & 1.04 .0 & 470 & 8 \\
ALOS & NASDA, Japan & 2004 & PAN & 2.5 & 691 & 35.70 \\
\hline
\end{tabular}

Note: $P A N=$ Panchromatic: $M S=$ Multispectral (after Jacobsen, 2003).

The aim of the paper is to review methodology of creating a digital database of urban area using high resolution satellite imagery for establishment of topographic information with the following objectives:

- Compare the use of traditional photogrammetric method and remote sensing method for the production of topographic map.

- Investigate the production techniques of using high resolution satellite imagery to produce GI products such as Digital Terrain Model (DTM), Digital Orthophoto Map (DOM) and Digital Line Graph, here specifically refers to Digital Terrain Feature data (DLG) or Vector Map, and identify the adequate procedure including Quality Control.

- Makes recommendations on the most adequate techniques in the production of digital topographic map.

\subsection{Research Question}

- What are the advantages and disadvantages of topographic map production using high resolution satellite images compared with aerial photograph?

- How can quantity control be improved on geoinformation product?

- What are the limitations of this project, that is, areas where investigation should be carried out in the nearest future?

\section{Conceptual Framework}

\subsection{ATKIS Concept}

The Authoritative Topographic-Cartographic Information System (ATKIS) is a multistage research and development project of the Federal Republic of Germany State Survey Working Committee (ADV) in the fields of state Survey, cartography and automation.

\subsection{The Aims of ATKIS}

- To provide the user with a simple and reliable source of digital topographic data for integration with their own data sets.

- To ensure that the topographic data are authentic and up-to-date.

- To improve the overall efficiency of information gathering, processing and output.

ATKIS is based on modern cartographic model theory. The real world with its topographic objects and its thematic structure is viewed as the original. The topographic survey creates the primary model, a topographic landscape model. This model is transformed through cartographic work into a secondary model, the cartographic landscape model. During both stages generalization process at various levels take place resulting in different degree of detail.

ATKIS provide for the changing demand from analogue to digital storage of a common topographic information system that will ensure that up-to-date data is captured and maintained in the computer.

ATKIS is use to maintain a standardized digital topographic database with a $3 \mathrm{D}$ dimensional structure, the database will contain Digital Landscape Models (DLM). The DLM will contain the captured topographic objects of the landscape in digital form with geometric integrity. The content of the DLM is stored in an object class catalogue, structured by object themes, object groups, and object class. The DLM stores data whose detail varies with the DLM information density. The digital interpretation of aerial photography and the digitizing of land scale base maps and 
other topographic state maps in raster and vector format are the major methods used in the capture of the information. The Digital Cartographic Model (DCM) contains topographic information, being transferred to cartographic representation according to scale and specific drawing rules. The content of DCM is outlined in the symbology catalogue (ATKIS-SK). (Fig.1)

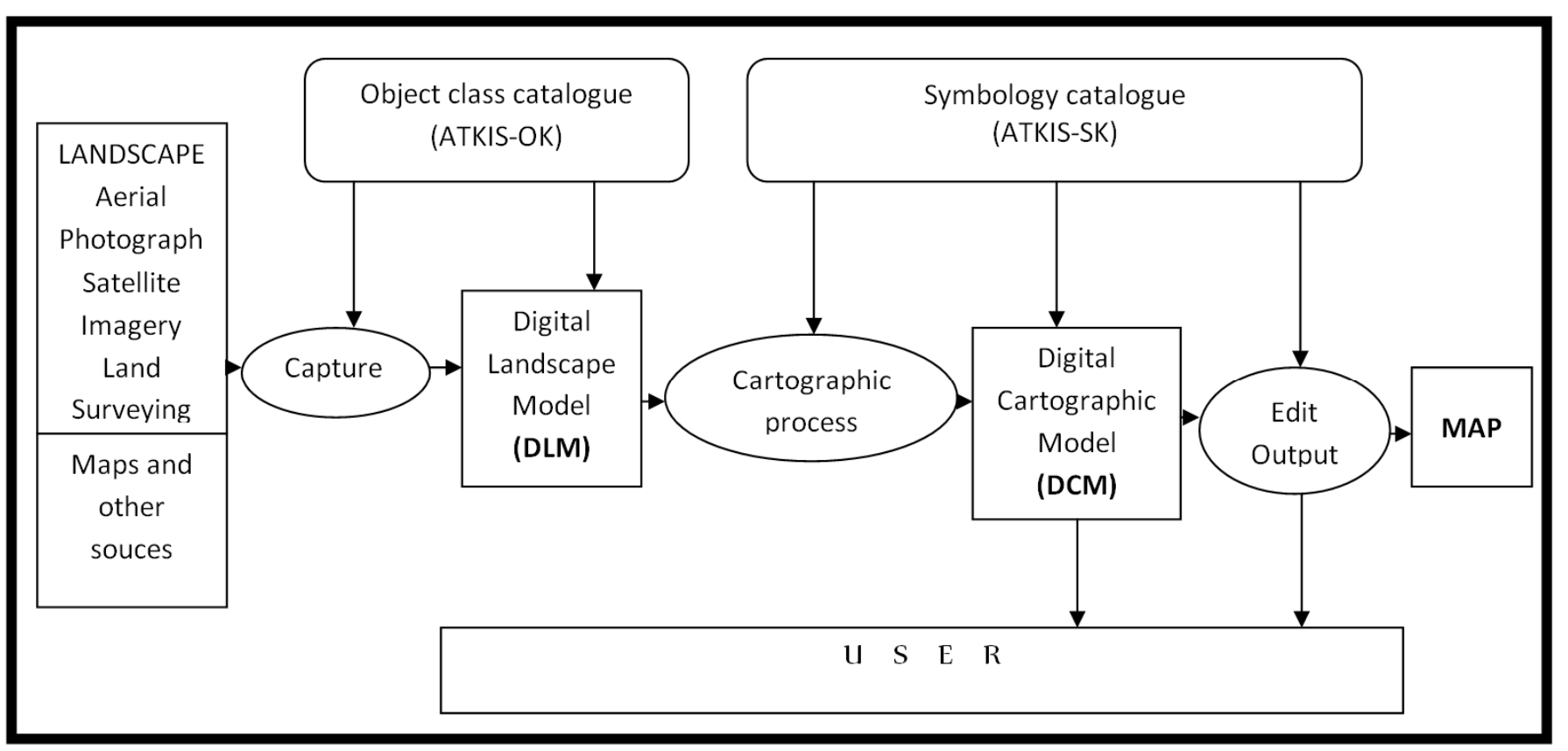

Fig. 1. Information flow of ATKIS (Adapted from ATKIS report).

\subsection{Content of the Digital Landscape Models (DLM)}

A DLM contains the three-dimensional (3D) structured topography of the landscape in the form of digitally stored topographic objects. Object position and the shape are scaled independently and geometrically defined by Universal Transverse Mercator (UTM) coordinates and height above mean sea level. DLM objects are not transformed into cartographic symbology.

All objects can be structured and combined into objects types. These types are categorized into object groups under the following objects themes:

1. Control Points

2. Settlement

3. Transportation

4. Vegetation

5. Hydrographic

6. Areas

7. Hypsography (Relief)

For structural reasons, it is logical to separate the twodimensional (2D) themes 1 to 6 from the remaining threedimensional (3D) hypsography (relief) theme. The first six themes make up to Digital Situation Model (DSM) while the relief results in the Digital Terrain Model (DTM). The DTM store the relief in a grid fashion by $3 \mathrm{D}$ coordinates and can therefore approximate the surface of the earth with the desired accuracy. The first six themes are two-dimensional, and they are referred to as Digital Situation Model (DSM), while the three dimensional relief themes singularly make up a Digital Terrain Model (DTM). There is an object class catalogue, ATKIS-OK, which defines the content of the
DLM, ATKIS- OK is used for structuring and classification of the landscape into topographic objects.

\subsection{DLM-Data Model}

From the topographic point view, the DLM is a set of topographic elements (units) which are referred to as DLM objects.

Each topographic object in the landscape is represented by exactly one DLM objects within the data model. A DLM object can consist of a number of objects parts. DLM objects can exist within a hierarchy of DLM objects of a higher order. Objects are defined by object class (as defined in the objects catalogue) and attributes. The ATKIS- OK contains rules for the creation of DLM objects of a higher order (by accumulating several DLM objects). The structure of the DLM data model is shown in Figure 2.

The structure of the DLM data model covers three major information aspects on three levels namely,

- The semantic aspect of the DLM objects and the DLM objects parts,

- The topological information aspect of the DLM objects and.

- The geometric information aspect of the DLM geometry elements.

The possible relationship between these data elements are shown as 1:n, n:1, 1:2 and 2:1. This data description allows the non-redundant storage of geometry together with implicit topological relationships. Explicit topological relationship between DLM object parts are possible. 


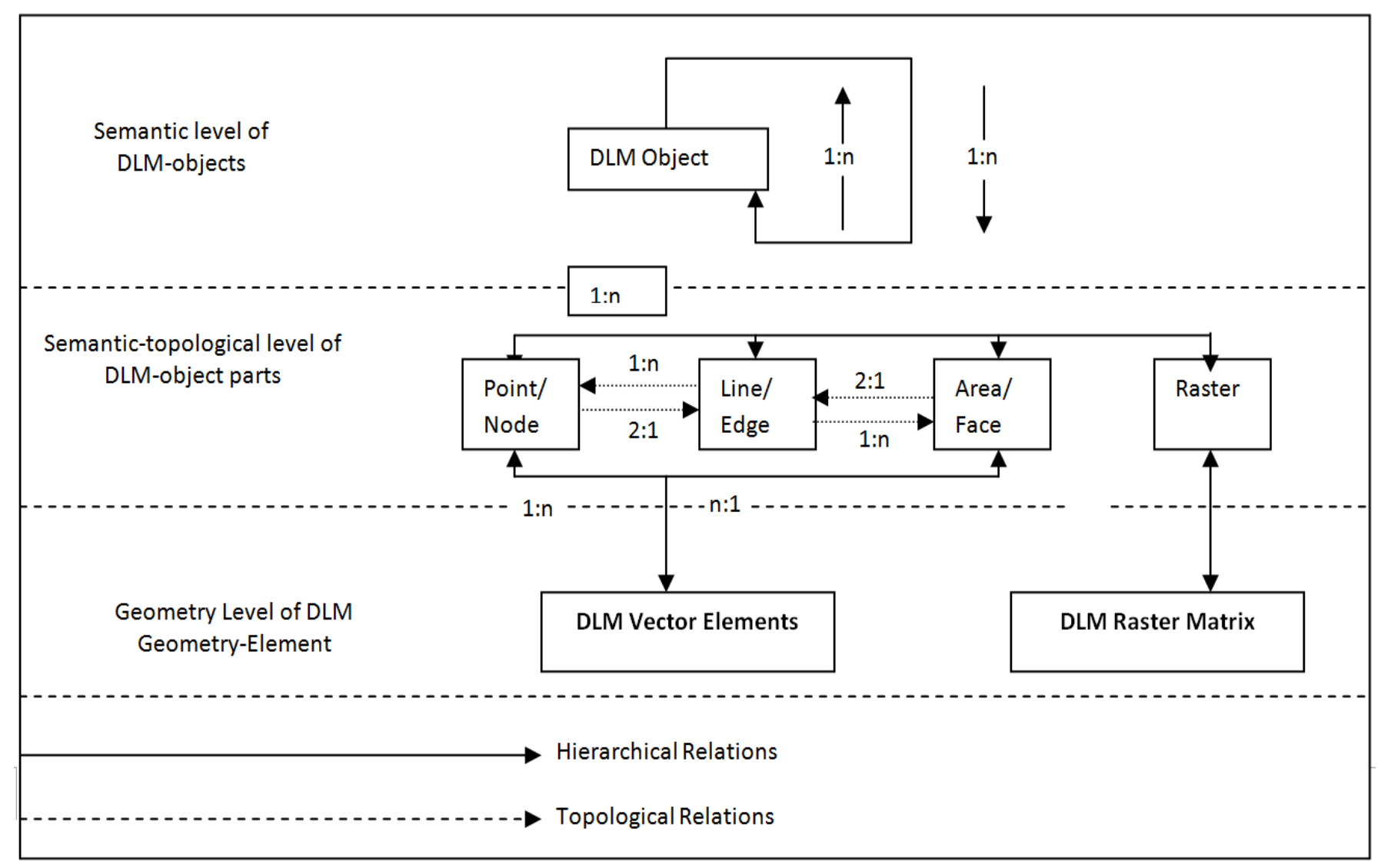

Fig. 2. Structure of DLM data Model (Adapted from ATKIS project report).

For every DLM objects there has to be at least one object part. DLM object parts are created under semantic or topological criteria. They can be of area (face), line (edge), point (node) or raster type. DLM objects parts carry an ID number and are, like the DLM objects attributed, thus cannot have a name. Each object part is referenced to a unique object. Transitional references are used to distinguish between 'above' and 'below' when object parts cross each other. Where needed height value are stored in the attributes of object parts.

The geometric elements known as 'DLM vectors elements' and 'DLM raster matrix' are the real carrierrs of the geometric information and they belong to the geometric information level. They describe coordinates for points and interpolation method for lines, as well as raster data. The DLM vector element is used for the description of point, line or area objects part. A height value can be stored beside the positional values.

To avoid geometric redundancy, any DLM vector element can belong to several DLM object parts. The geometric description for DLM object parts of the raster type can be found in raster matrices, e.g. digital terrain model data.

\subsection{Content of the Digital Cartographic Models (DCM)}

A Digital Cartographic Models (DCM) contains selected and partially displaced objects according to the room needed by the symbols on the map sheet to be derived. The DLM contains selected and partially displaced objects according to the space needed by the symbols on the topographic maps to be derived.

The symbology catalogue, ATKIS- SK, associates symbols to topographic objects and therefore defines the content of the DCM. Depending on the ATKIS-SK, and its degree of generalization, a number of DCM versions may be produced.

\subsection{DCM-Data Model}

From the cartographic view point, the model consists of many 'cartographic units' or DCM objects. Any DCM object point points to a number of cartographic sub-unit or DCM object parts. The creation of DCM objects parts or the graphical presentation of DLM objects can however; result in a modified view of the DCM data model. The structure of the DCM data model is shown in Fig. 3.

The basic concept is similar to that of considering DLM in one information system; the DCM objects have a model type store for differentiation. DKM objects are formed DCM object parts. These parts can be point, line, area, and text or pixel array. They carry symbology catalogue. DCM vector elements are used for the description of position and shape of DCM object parts. In contrast to the DLM vector elements, there is no height stored for DCM vector elements. 


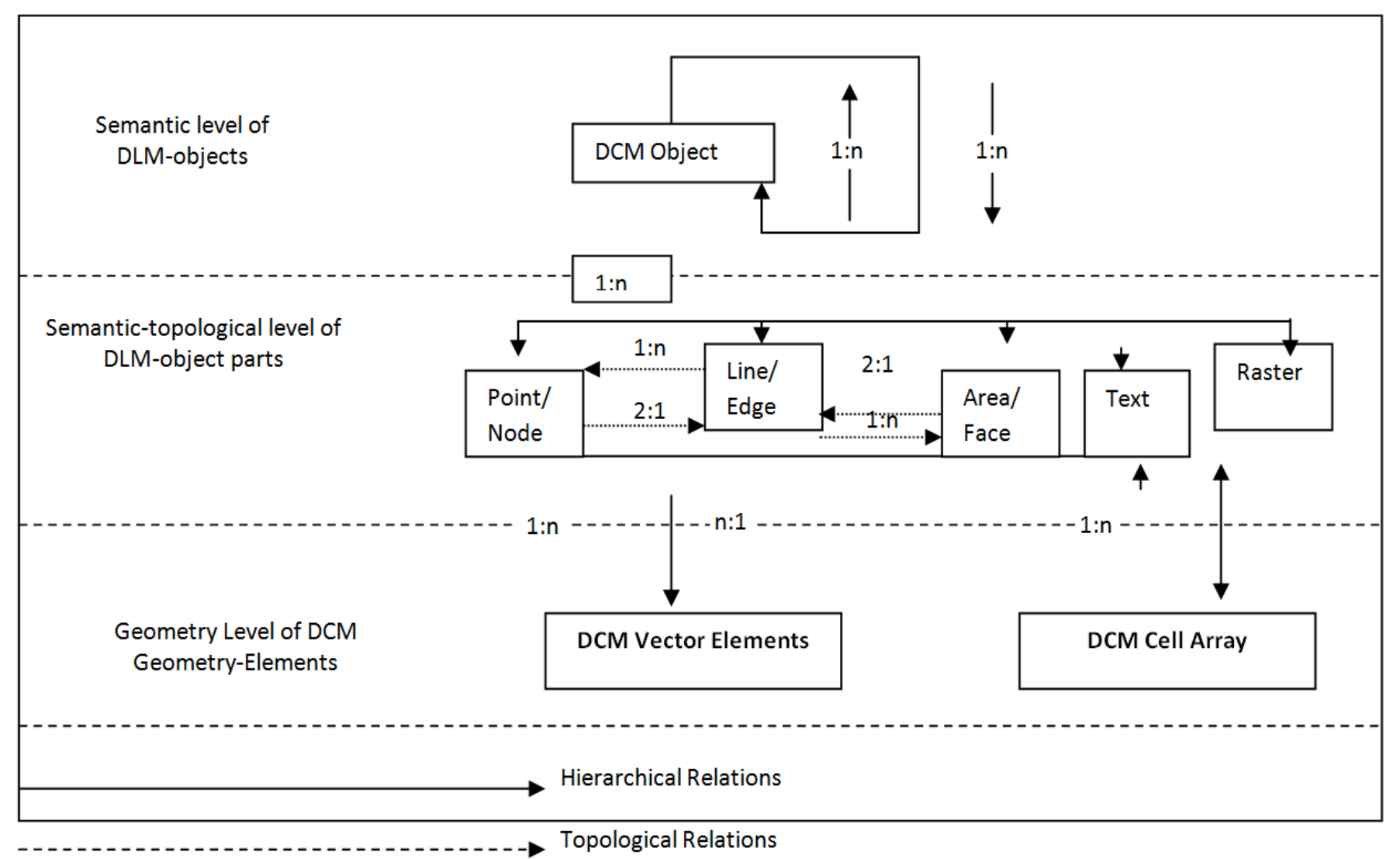

Fig. 3. Structure of DCM data model (Adapted from ATKIS project report).

\section{Basic Concepts of Mapping}

\subsection{Maps and Mapping}

A map is used to visualize geospatial data, which refers to the location or the attributes of objects or phenomena located on Earth (Kraak \& Ormeling, 1997). From the map, information on distances, directions and area sizes can be retrieved, pattern revealed, and relations understood and quantified. With the development of relevant techniques, came many kids of new map formats, such as on-screen map, web map. Whether on paper or on a computer screen, a map is the best tool available to catalog and view the arrangement of things on the Earth's surface.

Mapping, namely cartography, is referred to the act or process of making a map. According to Kraak \& Ormeling (1997) "nowadays cartography is seen as the conveying of geospatial information by means of map: this means not only the manufacturing of maps but also their use is regarded as belonging to the field of cartography.

\subsection{Map Updating}

Today maps of most parts of the world already exist and very often also with the required scale. Maps have to be up to date; it means maps must be changed in accordance with the changes in the real world, and must be completed in relation to the specified scale, geometric and thematic accuracy (Jacobsen, 2002). Generally speaking, in urban areas map updating is required in a shorter time interval than in the rural areas. In some cases the changes may be rapid in other cases slow. Map updating is the process of bringing up to date features on the map which had change over a period, the quality standards, including the geometric accuracy, must be respected. Map updating programs have to perform the change detection in which the old map and new data sources are compared with each other in order to distinguish the changes that happened in the real world. If the changes are very large, then it may be more economical to generate a completely new map instead of updating the old one.

\subsection{Main Products of Spatial Data}

Today, the main products of spatial data are Digital Terrain Model (DTM) or Digital Elevation Model (DEM), Digital Orthophoto Map (DOM, or orthophotos), and Digital Line Graph (DLG), here specifically refers to Digital Terrain Feature data. DTM is a $3 \mathrm{D}$ digital representation of the Earth's terrain relief (Lucas et al, 2001). A DTM represents the elevation associated with the Earth's terrain and not necessarily the human-made (e.g. buildings) or natural (e.g. trees) features located on the earth's surface (Lucas, 2003). It can be stored in different manners (contour lines, TIN, Raster). DEM is a special case of a DTM, a DEM stores terrain elevation (surface height) by means of a raster. 
Elevation refers to a height expressed with respect to a specific reference (Jacobsen, 2003).

Beside DTM and DEM, there is another terminology DSM (Digital Surface Model) which represents the elevation associated with the earth's surface including terrain relief and all natural or human-made features located on the Earth's surface. The primary different between them is that the DTM represents the Earth's terrain relief whereas a DSM represents the Earth's surface (Tiejun, 2005).

\subsection{Digital Terrain Model (DTM)}

DTM is an important kind of geo-information product in itself and is vital for creating orthorectified images and many other applications. Various techniques and approaches can be used to create a DTM, which vary with respect to the technology for collecting elevation information from the Earth's surface and enhancing quality. Meanwhile, many researches focus on automatic DTM collection. Such different techniques include:

a. Ground surveying: This approach uses equipment such as GPS (Global Positioning System). Total Station and level, it is highly accurate but time consuming.

b. Photogrammetry: Photogrammetric techniques are highly accurate but require high-level expertise. It includes semi-automatic digitizing contour lines or fully automatic image matching (but still needs manual editing if high accuracy wanted).

c. Digitized topographic maps: this process is not as accurate, but less cost. Furthermore, it is an alternative for the regions where up to date images are not available.

d. New methods such as microwave Radar (SAR interferometry) and light detection and ranging (LIDAR) are also becoming available and operational (Baltsavias, 1999).

Each approach has its advantages and disadvantages. The optimum approach depends on local condition (access to data sources, available equipment and expertise, delivery schedule and demands of DTM (such as the accuracy and the cost aspects etc).

\subsection{Digital Orthophoto Map (DOM)}

Digital Orthophoto Map (DOM), normally refers to an orthographic photograph (commonly known as an Orthophoto). This contains terrain features in fine detail. And plus some cartographic features (such as grid annotation, contour line etc). Here DOM is used as a synonym of an orthoimage which is a geometrically corrected air photograph or satellite image. DOM has been corrected for terrain relief. As a result, it can be used directly in combination with geocoded data (Janssen \& Huurneman, 2001). It has some advantages such as sufficient resolution, sufficient precision, abundant information, simple data structure, quick production and short update period (so it has strong present-time characteristic).

The orthoimage has the geometric characteristics of a map and the image qualities of a photograph. The objects on an orthoimage are in their true orthographic positions. Therefore orthoimage are geometrically equivalent to conventional line and symbol planimetric maps. Any measurement taken on an orthoimage reflects a measurement taken on the ground. The first orthoimages were produces in the 1960s and at that time it was a time consuming and expensive produce. However due to recent advances in related technologies orthophotos can now be produced speedily and easily ( $\mathrm{Li}, 1998)$.

\subsection{Digital Line Graph (DLG)}

DGL is defined by the USGS (United State Geological Survey) as "digital vector representations of cartographic information of topographic and planimetric map features which are derived from aerial photographs, remote sensing images, cartographic sources materials and related sources" (McEwen, 1984; http://www.usgs.gov). In this research, DLG refers to digital terrain features data specifically. Except terrain relief, it contains all the elements on the digital topographic map as this is the most important kind of conventional vector map presenting spatial data. The world's oldest known topographic map dates back to 2300 BC (Tempfli, 1998). DLG consists of all terrain features including man-made (e.g. buildings, roads) or natural (eg. Rivers, trees) features. All the aspects of it such as accuracy, resolution, scale representation and so on are the same as topographic map but without terrain relief (contours).

\section{Mapping Related Techniques}

\subsection{Data Sources for Mapping}

The most important data sources for mapping are:

\subsubsection{Field Survey Data}

It is the most traditional data source but takes more time and also expensive in terms labour and cost. General they are used for ground surveying and filed completion or applied to some special situation for example very small area where there are no other data sources or where there is the need for urgent demand with high accuracy.

\subsubsection{Aerial Photograph}

Prior to the 1960s our view of the earth was restricted to photographs taken by surveying camera mounted on the airborne platform using visible light and invisible thermal infrared (heat) energy which is reflected or emitted in varying degrees by natural and synthesis objects. Analogue photographs are the most vital characteristic of classic aerial Photogrammetry. (Mikhail et al, 2001).

\subsubsection{Satellite Imagery}

Many Commercial HR satellites are now in orbit and even more are planned for the coming years which will revolutionize land surveys. Especially the high spatial resolution satellite images can be the candidates for mapping in competition to aerial photographs. The table below gives some selected technical specifications of the HR Satellite which are important for mapping applications. The basic information of several of the most famous HR satellite 
images i.e. IKONOS, Quick Bird, and Orbview-3 (Toutin, 2002).

Table 2. Some technical specification for the HR RS.

\begin{tabular}{ll}
\hline Item & Technical Data \\
\hline Ground resolution & $0.5 \mathrm{~m}$ to $3 \mathrm{~m}$ \\
Orbit height & 460 to $680 \mathrm{~km}$ \\
Focal length & Up to $10 \mathrm{~m}$ \\
Image recording & CCD linear or frame arrays \\
Stereo mode & In-track and/or cross-track stereo \\
Base-height ratio & 0.6 to 2.0 \\
Ground swath width & 6 to $36 \mathrm{~km}$ \\
Revisit rate & 1 to 4 days (depending on latitude) \\
\hline
\end{tabular}

Source: Jacobsen, K. (2003)

\subsection{Digital Photogrammetry}

Photogrammetry is the art, science and technology of obtaining reliable information about physical objects and the environment through the process of recoding, measuring and interpreting photographic images and patterns of electromagnetic radiant imagery and other phenomena. Digital techniques have become widely available from 1990's and allow a high degree of automation. Where there is need for mass production of many different kinds of products in a short time, this can be done on the digital photogrammetric system (DPS), by applying digital image processing techniques (Tiejun, 2005).

\section{Summary}

This work takes an overview of the use of high resolution imagery for establishment of topographic information, it also review some modern techniques of map making, high resolution imageries. It shows that with the rapid and successful advances in remote sensing, GPS and GIS technologies in the mapping sciences, coupled with the expected increase in the number of sensors for sub-metre (spatial) resolution satellite images, the sustainable development of the region with economic and political stability of its countries is assured. But the success of this is dependent on the development of spatial data infrastructures at National and Regional levels.

\section{Conclusion}

Remote sensing provides a rapid urban inventory on the earth's surface which can then be extracted, processed, stored, analyzed, retrieved and presented in various forms with the aid of GIS technology. When properly implemented, therefore remote sensing and GIS technologies can facilitate a rapid sustainable development of the region including an efficient management of the urban expansion.

The Cartographic systems/organizations, at state or national level, are finding it increasingly difficult to cope with the needs and aspirations of the public, as the public require current and adequately accurate information of diverse and complex nature, there is need to modernising the present systems drastically with a view to making them available to various organizations in the most economical, faster and convenient manner for optimal resources management.

\section{References}

[1] Akingbade, A. O (2005): "Improvement of Availability of Land Registration and Cadastral Information in Ondo State, Nigeria" Thesis submitted to the International Institute for Geo-information Science and Earth Observation (ITC) in partial fulfillment of the requirements for the degree of Master of Science in Geo-informatics.

[2] ATKIS (1988): The Authoritative Topographic -Cartographic Information System (of the German State Authoritative and the Institute of Applied Geodesy (IFAG). The Federal Republic of Germany State Survey Working project report. Pp. 5-6, 7, 12-17.

[3] Baltsavias, E. P. (1999): “A comparison between Photogrammetry and Laser Scanning” ISPRS Journal of Photogrammetry \& Remote Sensing. Vol. 54 No 3.

[4] ESRI (2004): “Cartographic Design Process: Artistic Interpretation with the Geodatabase". An ESRI White paper ESRI 380 New York St, Redlands, CA, USA. Pg. 1-6.

[5] Huixian, X. (2005): "Interpretability and accuracy of high resolution space images for 1:10,000 topographic mapping of China". Thesis submitted to the International Institute for Geo-Information Science and Earth Observation (ITC) in partial fulfillment of the requirements for the degree of Master of Science in Geo-information Science and Earth Observation pp. 1-2.

[6] Jacobsen, K (2003): Geometric Potential of IKONOS and QuickBird Imageries. "In D. Ritsch (ed) Photogrammetric Week 2003, Hanover. Pp 101-110

[7] Jacobsen, K (2002): "State of the Art Trends in MappingPast, Present and Future". INCA workshop, Ahmeadad. Janssen, L. L. F and Huurmeman (2001): "Principles of Remote Sensing" ITC Educational Textbook Series. Enchede, the Netherlands.

[8] Kelete, B (2004): "Redesign of workflows for Topographic production process at the Ethiopian Mapping Authority". Thesis submitted to the International Institute for Geoinformation Science and Earth Observation (ITC) in partial fulfillment of the requirements for the degree of Master of Science in Geo-information Management. Pg. 3.

[9] Kraak, M. J \& Ormeling, F. J. (1997): "Cartography: Visualization of Spatial Data "Addison Wesley Longman Limited, Harlow pp. 12-15, 42, 60.

[10] Li, R. (1998): Potential of High Resolution Satellite Imagery for National Mapping Products, Photogrammetric Engineering \& Remote Sensing Vol. 64, No 12. Pp. 1165-1169.

[11] Tempfli K (1998): (2003) "Business of National Mapping Organizations" Lecture Notes, ITC, Enschede, the Netherlands

[12] Tempfli, K (1998): "3D topographic mapping for urban GIS". ITC Journal Vol. 3 No 4. 
[13] Tempfli, K (1998): "Urban 3D topologic data and texture by digital photogrammetry" In ASPRS RTI Annual Conference, Tampa, USA.

[14] Toutin, T (2002): "Mapping Potential of High Resolution Satellite Imagery, Natural Resources Canada, Vol. No. 2.

[15] Tiejun, W (2005): "The capability of IKONOS images for mapping in China". Thesis submitted to the International Institute for Geo-information Science and Earth Observation (ITC) in partial fulfillment of the requirements for the degree of Master of Science in Geo-informatics Pg 7-9.

[16] McEwen, A (1984): "USGS digital Cartographic data Standards: National Mapping Program, US GeoData, Reston, USA.
[17] Mikhail, E. M. Bethel, J. S. and McGlone, J.C. (2001): "Introduction to Modern Photogrammetry". Wiley \& Sons, New York.

[18] http;//www.usgs,gov, United State Geological Survey

[19] http://www.itc.nl

[20] http://esri. Com

[21] http://www.adv.de

[22] http://www.emap-int.com 